\title{
Potências médias e potências emergentes na economia política internacional: uma aproximação teórico-conceitual
}

\author{
Middle and emerging powers in the international \\ political economy: a theoretical and conceptual \\ approach
}

\section{Las potencias medianas y emergentes en la economía política internacional: un enfoque teórico y conceptual}

\footnotetext{
iD (9) Daniela Vieira Secches

Pontifícia Universidade Católica de Minas Gerais, Belo Horizonte, Minas Gerais, Brasil dsecches@pucminas.br

iD Javier Alberto Vadell

Pontifícia Universidade Católica de Minas Gerais, Belo Horizonte, Minas Gerais, Brasil javier.vadell@gmail.com

iD (9)onardo Ramos

Pontifícia Universidade Católica de Minas Gerais, Belo Horizonte, Minas Gerais, Brasil Icsramos@yahoo.com.br
}

Resumo: As Relações Internacionais no novo milênio apresentam novos e renovados fluxos de interação entre uma pluralidade considerável de atores e temas. Nesse contexto, uma reflexão mais profunda sobre o poder estatal e as potências emergentes torna-se de extrema relevância. Para tanto, será aqui apresentado o debate teórico sobre o conceito de potências médias e emergentes na Economia Política Internacional. O objetivo é traçar uma revisão teórica que permita delinear algumas considerações sobre as pos- 
sibilidades e os limites analíticos desses conceitos na contemporaneidade.

Palavras-chave: Potências médias. Potências emergentes. Economia Política Internacional.

Abstract: International Relations in the new millennium present new and renewed interaction flows among a great number of actors and themes. In this context, a deeper reflection on state power and emerging powers becomes extremely relevant. Therefore, we will present the theoretical debate on the concept of emerging and middle powers in International Political Economy. The objective is to provide a theoretical review that allows us to outline some propositions on the analytical possibilities and limits of these concepts in contemporary times.

Keywords: Medium Powers. Emerging Powers. International Political Economy.

Resumen: Las relaciones internacionales en el nuevo milenio presentan nuevas y renovadas corrientes de interacción entre una considerable pluralidad de actores y temas. En este contexto, una reflexión más profunda sobre el poder estatal y las potencias emergentes se vuelve extremadamente relevante. Con este fin, se presentará aquí el debate teórico sobre el concepto de potencias emergentes y medias en la Economía Política Internacional. El objetivo es proponer una revisión teórica que nos permita delinear algunas consideraciones sobre las posibilidades y los límites analíticos de esos conceptos en los tiempos contemporáneos.

Palabras clave: Potencias medianas. Potencias emergentes. Economía política internacional.

Data de recebimento do artigo: 10/02/2019

Data de aprovação do artigo: 16/05/2019 
Embora não se possa definir a política exclusivamente em termos de poder, é seguro dizer-se que o poder é sempre um elemento essencial da política. Para se entender um assunto político, não basta (como bastaria no caso de uma questão legal ou técnica) saber do que se trata. É necessário, também, saber quem está envolvido.

(CARR, [1939] 2001, p. 135)

O campo das Relações Internacionais sempre teve como uma de suas preocupações centrais a ideia de poder. Ao se propor como objeto o estudo das relações de cooperação e de conflito entre atores correlacionadas à esfera internacional, os debates da área, em alguma medida, flertam com a capacidade de esses personagens influenciarem o curso de ação de outros ou modificarem mesmo condições estruturais - em uma acepção mais abrangente sobre poder. A despeito dessa angústia comum, suas diversas abordagens teóricas seguiram caminhos distintos no trato desse conceito, especialmente no que diz respeito aos indicadores de poder, à relação entre poder potencial e poder real, e à dinâmica entre agente e estrutura na constituição e nos desdobramentos dessa capacidade de influência.

Objetiva-se, no presente trabalho, apresentar, de uma perspectiva crítica, um estado da arte do conceito de potência emergente na Economia Política Internacional. A hipótese ora apresentada indica a ausência de um consenso sobre como entender e aferir o poder, o que leva à dificuldade, no estado da arte da disciplina, de qualificar uma potência emergente. No entanto, esse imbróglio teórico-metodológico acaba por enriquecer a discussão e indica a relevância das investigações sobre potências emergentes, a fim não só de promover o avanço acadêmico, mas aumentar sua capacidade de previsão e de prescrições de ações práticas.

Assim, o texto inicia-se com uma revisão bibliográfica sobre o conceito de potência emergente na Economia Política Internacional, com o objetivo de levantar seus principais modelos (Seção 1). A revisão bibliográfica guiou-se pelas publicações canônicas da Economia Política Internacional sobre o tema desde o sur- 
Potências médias e potências emergentes na economia política...

Daniela Vieira Secches · Javier Alberto Vadell • Leonardo Ramos

gimento do debate, na academia canadense, em 1946. As obras estudadas e classificadas foram escolhidas a partir das revisões empreendidas por Sennes (1998) e Huelsz (2009). O levantamento e a classificação dessas obras, segundo a abordagem dada ao conceito de potências médias, pode contribuir para identificar pontos de consenso e problematizar as implicações práticas de se trabaIhar com diferentes definições.

Em seguida, serão consideradas as diferenças entre potências emergentes e potências médias tradicionais (Seção 2). Considerando a hipótese ora aventada de que a dificuldade de se definir potências emergentes deriva da ausência de consenso sobre o conceito de poder no campo, a Seção 2 buscará contribuir para o esclarecimento dessa relação ao contrapor o processo de emergência ao conceito de potência média tradicional. Por fim, tecer-se-ão considerações finais relacionando a classificação proposta sobre as definições de potência emergente com o conceito de poder, com o intuito de problematizar o dissenso em torno dessa relação e suas implicações teórico-metodológicas para o avanço de tais discussões no âmbito da Economia Política Internacional (Seção 3).

\section{As potências nas Relações Internacionais: breve revisão teórica na Economia Política Internacional}

Para compreender como a ideia de poder pode ser desdobrada no conceito de potência, os modelos teóricos encontrados na Economia Política Internacional apresentam uma interessante opção: a capacidade de reunir elementos desse subcampo e as abordagens teóricas gerais de Relações Internacionais. Uma revisão teórica sobre como autores da Economia Política Internacional abordam o conceito de poder e de potência pode colaborar para melhor explicar sua hierarquização em múltiplos aspectos, seja como grande potência, seja esclarecendo o potencial explicativo de poderes emergentes. Esses modelos procuram investigar qual Estado concentra mais poder, como medir essa concentração e 
seus desdobramentos geopolíticos, econômicos e institucionais. Nesse sentido, é interessante observar a proximidade entre o conceito de potência emergente e potência média. A partir de uma interpretação literal do termo, pode-se entender potência emergente como um ator intermediário em uma hierarquia de poder. Se, por um lado, não mais está em uma posição inferior, pois emerge, ainda não pode ser entendido como grande potência, pois está em processo de ascensão.

A partir da segunda metade do século XX, começam a surgir os primeiros debates teóricos no campo sobre potências médias e emergentes (HUELSZ, 2009, p. 12; GIACCAGLIA, 2014). Originalmente desenvolvidos na academia canadense após a Segunda Guerra Mundial como forma de fornecer substrato para as pretensões de política externa do país, seguiram-se várias abordagens sobre o conceito. A partir de uma análise cruzada sobre as propostas de Cornelia Huelsz (2009) e de Ricardo Sennes (1998), propõe-se uma classificação sobre os modelos teóricos aplicados para potências médias e emergentes em seis tipos, conforme indicado na tabela abaixo.

Tabela 1. Modelos teóricos aplicados à análise de potências médias e emergentes a partir da segunda metade do século XX

\begin{tabular}{|c|c|}
\hline MODELO TEÓRICO & AUTORES ${ }^{1}$ \\
\hline Funcional & $\begin{array}{l}\text { Gelber (1946) } \\
\text { Wood (1987) }\end{array}$ \\
\hline Comportamental & $\begin{array}{c}\text { Lima (2013) } \\
\text { Cooper, Higgot e Nossal (1993) }\end{array}$ \\
\hline Sistêmico-estrutural & $\begin{array}{c}\text { Schneider }(1977) \\
\text { Selcher }(1981,1983,1986)\end{array}$ \\
\hline Comportamental-estrutural & $\begin{array}{l}\text { Keohane (1969) } \\
\text { Holbraad (1984) }\end{array}$ \\
\hline Inserção regional & $\begin{array}{c}\text { Osterud (1990) } \\
\text { Myers (1991) } \\
\text { Sennes (1998) }\end{array}$ \\
\hline Crítico & $\begin{array}{c}\text { Cox (1989) } \\
\text { Huelsz (2009) }\end{array}$ \\
\hline
\end{tabular}

Fonte: Elaborada pelos autores, com base em Cornelia Huelsz (2009) e Ricardo Sennes (1998).

1 Listagem não-exaustiva, apenas usada para ilustração. 
No modelo funcional de Gelber (1946, p. 279), desenvolvido no contexto das preocupações do Estado canadense com sua inserção internacional, ressalta-se que uma potência média não se confunde com uma grande potência, pois não tem uma capacidade temática ampla de ação. Ao contrário, ela tende a se concentrar em áreas específicas qualificadas pelo autor como questões funcionais, normalmente dotadas de significante conotação moral. Outra diferença entre potências médias e grandes potências poderia ser notada por meio da participação do Estado no Conselho de Segurança das Nações Unidas - uma potência média não seria um membro-permanente.

Próximo ao modelo funcional encontra-se o modelo comportamental, identificado no trabalho de Lima (2013) e Cooper, e Higgot e Nossal (1993). Para Lima (2013, p. 53-60), o que qualifica uma potência média como tal é a natureza multifacetada de seu comportamento na esfera internacional. Uma potência qualificada como média tenderia a combinar estratégias unilaterais, de carona, de proeminência regional, de liderança e de reação à coerção de terceiros Estados.

Cooper, Higgot e Nossal (1993, p. 12-32), ao contrário de Lima (2013), não apresentam uma análise genérica sobre a natureza do comportamento do que seriam potências médias. Os autores identificam áreas específicas, a partir de estudos de caso sobre o Canadá e a Austrália, nas quais atores com excedente médio de poder tendem a ser ativos, exercendo o que denominam como diplomacia de nicho. Por conseguinte, o que define as potências médias é sua maior concentração relativa de soft power, que se desdobra em um enfoque multilateral e na valorização de questões secundárias para o hegêmona, como direitos humanos e manutenção da paz.

Por seu turno, o modelo sistêmico-estrutural, de visão realista, define potência média a partir de sua posição em uma hierarquia de capacidades materiais definidas política e economicamente. Autores que trabalham nessa perspectiva selecionam indicadores estatísticos para construir essa escala, que decorre do estabeleci- 
mento de um limite superior a partir da definição de um hegêmona e de Estados-pivô ao seu redor, os quais representariam potências médias. Um Estado-pivô seria definido a partir de seu impacto potencial para a estratégia de ação do hegêmona - contemporaneamente estabelecido como os Estados Unidos da América (EUA) (HUELSZ, 2009, p. 32-36). Pode-se considerar alguns dos modelos citados por Ricardo Sennes (1998, p. 387) dentro do modelo sistêmico-estrutural. Schneider (1977) e Selcher (1983) buscam aferir o poder de um Estado a partir de variáveis estatísticas como território, população, produção econômica, bem-estar, insumos militares, posição diplomática e comércio exterior.

Keohane (1969) propõe um modelo comportamental-estrutural, que considera a posição ocupada pelo Estado no ambiente internacional a partir da maneira pela qual o país atua. Os desdobramentos analíticos da proposta chegam a uma classificação quadripartite. As Grandes Potências seriam entes estatais capazes de moldar e determinar o sistema (system-determining), enquanto as Potências Secundárias seriam system-influencing, ou seja, não determinam isoladamente a estrutura, mas conseguem influenciar a sua forma. As Potências Pequenas apenas conseguiriam afetar o sistema enquanto membros de coalizões com potências maiores (system-ineffectual).

A quarta classificação descrita por Keohane (1969, p. 300) seria o conceito de potência média mais utilizado no campo, segundo Huelsz (2009, p. 37). Para o autor, potências médias seriam Estados que afetam o sistema por meio de alianças e/ou organizações internacionais (system-affecting) (KEOHANE, 1969, p. 301). Haveria na atuação desse tipo de potência um elemento psicológico, o qual residiria no fato de que são os líderes dos Estados que podem ser qualificados como os responsáveis por considerar a aptidão do país para agir sozinho com um impacto menor ou para maximizar sua ação por meio da atuação coletiva em grupos ou em instituições internacionais.

A abordagem de Holbraad (1984) para potências médias pode igualmente ser considerada dentro de uma linha comportamental- 
Potências médias e potências emergentes na economia política...

Daniela Vieira Secches · Javier Alberto Vadell • Leonardo Ramos

-estrutural. O autor, primeiramente, indica o que considera como potências médias usando os Produtos Internos Brutos (PIBs) e o tamanho da população de um dado país. Apesar de metodologicamente flertar com o modelo sistêmico-estrutural, Holbraad (1984, p. 68-74) busca desdobrar sua análise considerando o padrão de comportamento e a função internacional exercida pelos Estados considerados como potências médias. Por fim, o autor retorna à noção sistêmica ao procurar entender como ordenamentos internacionais com distribuição de poder distintas interferem nesse comportamento e nessa função, passando pela dimensão regional.

O modelo de inserção regional qualifica a potência média a partir do grau de relevância que um dado Estado tem para sua região. Ao invés de trabalhar com o conceito de potência média propriamente dito, Osterud (1990, p. 12) propõe a qualificação de Grande Potência Regional. Esse título seria derivado do cumprimento de três características indicadas pelo autor: (1) identificação de um sistema regional ${ }^{2}$ onde o país atua; (2) capacidade desse Estado de se opor a coalizões de Estados na mesma região e (3) grau considerável de influência nos assuntos regionais. ${ }^{3}$

Myers (1991) entende que uma potência média define-se pela preponderância regional, que pode ser qualificada de quatro formas: (1) Estado hegemônico ou aspirante à hegemonia regional; (2) Estado que barganha na região pela proeminência; (3) Estado que depende perifericamente de outras potências para se sustentar como regional e (4) Estado externo à região que desafia o hegêmona regional. Sennes (1998) endossa as abordagens de Osterud (1990) e Myers (1991) e propõe reconhecer uma potência média a partir de três características, descritas na tabela abaixo.

2 Sistema regional pode ser entendido como um sistema geopolítico sobre o qual, ao longo do tempo, há a percepção de que as elites políticas reconhecem sua existência (MYERS, 1991, p. 1).

3 Para Osterud (1992), uma quarta característica possível, mas não definidora, seria a possibilidade de associação da Grande Potência Regional com outros tipos de potências. 
Potências médias e potências emergentes na economia política...

Daniela Vieira Secches · Javier Alberto Vadell • Leonardo Ramos

Tabela 2. Elementos de uma potência média e indicadores, segundo Sennes (1998, p. 403-404)

\begin{tabular}{|c|c|}
\hline ELEMENTO & INDICADOR \\
\hline Presença internacional & $\begin{array}{c}\text { Hierarquia de dados empíricos em comparação } \\
\text { com os demais Estados do sistema internacional. }{ }^{4} \\
\text { Capacidade de ação internacional. }{ }^{5}\end{array}$ \\
\hline Presença regional & $\begin{array}{l}\text { Presença geográfica, prioridade dos temas regio- } \\
\text { nais em sua agenda, tipos de ação diplomática } \\
\text { regional, laços econômicos em sentido amplo e } \\
\text { disputas políticas nas quais se envolveu regional- } \\
\text { mente. }\end{array}$ \\
\hline Comportamento internacional multifacetado 6 & $\begin{array}{c}\text { Alternância entre estratégias coerentes com a } \\
\text { vulnerabilidade e a autonomia demonstradas pelo } \\
\text { país. }\end{array}$ \\
\hline
\end{tabular}

Fonte: Elaborada pelos autores, com base em Ricardo Sennes (1998).

Cornelia Huelsz (2009, p. 38), inspirada em Cox (1989) e outros autores da chamada Economia Política Crítica, propõe um modelo crítico para a identificação e a análise das potências médias. A base do modelo é contrapor-se às perspectivas ortodoxas das abordagens realista, liberal e marxista das Relações Internacionais, aplicadas à Economia Política Internacional. Huelsz (2009, p. 58) faz aguda crítica a essas perspectivas por seu caráter excessivamente estadunidense e pela consequente abordagem acrítica sobre a produção do conhecimento, desconsiderando os problemas advindos de um dualismo duro que separa pesquisador e objeto.

A heterodoxia proposta pela autora envolveria um duplo movimento (HUELSZ, 2009, p. 58). Por um lado, uma compreensão simbiótica sobre as relações entre agente e estrutura, entre economia e política, evitando divisões artificiais fundadas em premissas explicativas e racionalistas. Ao contrário da tendência do que tem sido feito, a proposta é não qualificar potências médias apenas

\footnotetext{
4 Exemplos de dados empíricos seriam aspectos físicos, econômicos, demográficos, comerciais, diplomáticos e militares (SENNES, 1991:403).

5 A capacidade de ação internacional poderia ser medida pela agenda externa do Estado em questão, por como ele atua diante de acordos multilaterais, e pelo seu perfil econômico em sentido amplo (SENNES, 1991, p. 403).

6 Nesse ponto, Sennes (1991) converge com a perspectiva comportamental adotada por Lima (1986).
} 
Potências médias e potências emergentes na economia política...

Daniela Vieira Secches · Javier Alberto Vadell • Leonardo Ramos

em contraposição à estrutura com a qual interage, mas a partir da interpelação à sua agência, entendida não como mera consequência sistêmica. Por outro lado, faz-se necessária uma ampliação do conceito de poder além de sua dimensão material, a fim de incluir elementos ideológicos e políticos (COX, 1989, p. 825).

Tabela 3. Modelos teóricos sobre potências médias e seus limites (HUELSZ, 2009; SENNES, 1998)

\begin{tabular}{|c|c|c|}
\hline $\begin{array}{l}\text { MODELO } \\
\text { TEÓRICO }\end{array}$ & CONCEITO DE POTÊNCIA MÉDIA & LIMITES \\
\hline Funcional & $\begin{array}{l}\text { Estado que atua internacionalmente em } \\
\text { um conjunto temático limitado. }\end{array}$ & $\begin{array}{l}\text { Explicação circunstancial. Des- } \\
\text { considera a origem do poder. }\end{array}$ \\
\hline Comportamental & $\begin{array}{l}\text { Estado que atua internacionalmente de } \\
\text { uma forma característica. }\end{array}$ & $\begin{array}{l}\text { Minimiza fatores estruturais. } \\
\text { Diplomacia de nicho desdobra-se } \\
\text { como estratégia, não como causa } \\
\text { do poder. }\end{array}$ \\
\hline Sistêmico-estrutural & $\begin{array}{l}\text { Estado que congrega quantitativamente } \\
\text { um conjunto semelhante de caracterís- } \\
\text { ticas empíricas, o que o posiciona em } \\
\text { uma hierarquia intermediária no sistema } \\
\text { internacional. }\end{array}$ & $\begin{array}{l}\text { Ausência de consenso sobre os } \\
\text { indicadores empíricos, com hie- } \\
\text { rarquias resultantes distintas. }\end{array}$ \\
\hline $\begin{array}{l}\text { Comportamental-estru- } \\
\text { tural }\end{array}$ & $\begin{array}{l}\text { Estado que se comporta de uma deter- } \\
\text { minada maneira em relação ao sistema } \\
\text { internacional. }\end{array}$ & $\begin{array}{l}\text { Definição estática em relação à } \\
\text { estrutura. }\end{array}$ \\
\hline Inserção regional & $\begin{array}{l}\text { Estado que se destaca na sua dimensão } \\
\text { regional. }\end{array}$ & $\begin{array}{l}\text { Explicação tautológica. Inserção } \\
\text { regional vista como causa e } \\
\text { consequência da qualidade de } \\
\text { potência média. }\end{array}$ \\
\hline Crítico & $\begin{array}{l}\text { Estado que possui grau suficiente de au- } \\
\text { tonomia em relação às grandes potên- } \\
\text { cias e busca ambiente estável por meio } \\
\text { de instituições internacionais com vistas } \\
\text { a facilitar mudanças ordenadas (COX, } \\
\text { 1989, p. 827) na estrutura internacional. }\end{array}$ & $\begin{array}{l}\text { Conceito normativo-dependente, } \\
\text { construído em relação ao centro. }\end{array}$ \\
\hline
\end{tabular}

Fonte: Elaborada pelos autores, com base em Cornelia Huelsz (2009) e Ricardo Sennes (1998).

Percebe-se, assim, que os modelos teóricos convencionalmente empregados no campo apresentam pontos de convergência e de divergência, cada um indicando possibilidades e limites explicativos que fragilizam as respectivas abordagens ao objeto. Nesse sentido, tal exercício é útil na medida em que, a partir da contra- 
Potências médias e potências emergentes na economia política...

Daniela Vieira Secches · Javier Alberto Vadell • Leonardo Ramos

posição entre esses modelos teóricos, pode-se ter uma ideia mais clara sobre a diferenciação entre potências médias tradicionais e emergentes na literatura de Relações Internacionais e de Economia Política Internacional.

\section{Potências emergentes e potências médias: em busca de uma diferenciação teórica}

A despeito de ter se expandido de maneira desuniforme desde o século XVI, o capitalismo, como modo predominante de produção, encontra contraponto político no sistema moderno de Estados e suas modificações e evoluções influenciam-se mutuamente (RAMOS, 2013, p. 237). Partindo dessa premissa, observa-se que a história do século XX e a influência mútua entre o capitalismo como modo de produção dominante e o sistema de Estados refletiram-se nos debates teóricos sobre como abordar a noção de potência, que necessariamente perpassa a inter-relação entre aspectos econômicos e políticos. Ademais, o fim da ordem bipolar da Guerra Fria fez surgir novas agendas e dimensões geográficas para as relações internacionais, colocando, ainda, o aspecto regional em maior relevo (ZAHREDDINE, TEIXEIRA, 2015, p. 73).

Nesse contexto de coexistência de economias-mundo (WALLERSTEIN, 1990), é possível identificar três fases de surgimento de novas potências médias emergentes em relação às quais os modelos teóricos mencionados apresentam certo consenso sobre a periodização, a despeito das divergências sobre a aplicação desse qualificativo (COOPER, 1997). Dessa forma, o ponto de partida aqui defendido é que se entende potência emergente como potências médias surgidas após a década de 1970. ${ }^{7}$

\footnotetext{
7 Cooper (1997, p. 15) menciona três ondas de surgimento de novas potências. Inclui-se aqui na tipologia uma primeira "onda zero", que seriam as potências médias surgidas no pós-Segunda Guerra Mundial, fato empírico em torno do qual o próprio conceito começou a ser cunhado.
} 
Potências médias e potências emergentes na economia política...

Daniela Vieira Secches · Javier Alberto Vadell • Leonardo Ramos

Nos anos 1970, o Movimento de países Não-Alinhados representou um fórum a partir do qual novos Estados intermediários na hierarquia de poder da estrutura internacional apresentaram-se - Brasil, , Índia, lugoslávia e Indonésia. A segunda onda começaria nos anos finais da década de 1970 e se sustentaria até os anos 1980. Os atores aqui vistos como emergentes, como os associados aos Não-Alinhados, também eram críticos da estrutura vigente. No entanto, essas potências médias emergentes utilizavam-se de novos tipos de inciativas, além do mencionado fórum, a fim de impactar politicamente a estrutura. México, Nigéria e Argélia são exemplos disso.

A partir da segunda metade da década de 1980, novas potências médias poderiam ser encontradas, como Argentina e Malásia, por exemplo. A marca desses atores com novos excedentes de poder seria a atuação em coalizões, como o Grupo de Cairns. Por fim, Cooper (1997) indica algumas potências médias emergentes putativas pela sua posição geográfica ou pelo seu papel ativista, como Turquia e África do Sul. No novo milênio, novas ondas poderiam ser adicionadas a esse cenário geopolítico.

Cornelia Huelsz (2009, p. 12) atesta que grande parte dos trabalhos sobre essas novas potências médias partem dos conceitos anteriormente aplicados à "onda zero", ou seja, às primeiras potências médias qualificadas no pós-Segunda Guerra Mundial. Por conseguinte, é importante reconsiderar os modelos teóricos anteriormente mencionados a fim de perceber seus limites explicativos no que diz respeito aos Estados que ascenderam como emergentes nas três ondas indicadas por Cooper (1997), bem como aqueles com potencial de formar novas ondas de potências médias no novo milênio.

Uma primeira característica que pode ser recorrentemente percebida nesses novos atores médios é sua dupla capacidade de inserção - internacional e regional (SENNES, 1998, p. 400). Nolte (2007, p. 9) diferencia as potências médias tradicionais e emergen-

8 É oportuno destacar que, embora o Brasil nunca tenha participado diretamente do Movimento de Países Não-Alinhados dada a sua predileção por uma política externa mais autônoma e pragmática, ele participou de diversos encontros como observador (CERVO; BUENO, 2008). 
Potências médias e potências emergentes na economia política...

Daniela Vieira Secches ·Javier Alberto Vadell • Leonardo Ramos

tes também por essa referência ao seu modelo de inserção regional. Enquanto as primeiras definem-se de maneira funcional e comportamental, ou seja, pela função que exercem no ambiente internacional, os novos atores médios preocupam-se com a escala global por via de sua atuação na escala regional.

Cornelia Huelsz (2009, p. 70-72) propõe que potências emergentes necessariamente ascendem regionalmente. A despeito da pertinência desse indicador, quando pensados os casos empíricos acima mencionados, cabe lembrar a crítica de Schoeman (2000) sobre a tautologia em se definir um grau médio de poder a partir de sua circunstância regional, que se torna causa e consequência mesma do próprio qualificativo. ${ }^{9}$

Outra referência forte aos modelos de análise mencionados no item anterior remete às abordagens sistêmico-estruturais. Jordaan (2003) menciona, como diferenças constitutivas entre potências médias tradicionais e emergentes, a tradição democrática relativamente instável e recente nos novos atores; a posição semiperiférica deles na economia mundial e a desigualdade na distribuição da riqueza na esfera doméstica das potências emergentes. Esses dados empíricos refletem-se na segunda hipótese proposta por Huelsz (2009, p. 16):

Potências emergentes são os países que estão tradicionalmente situados em diferentes contextos estruturais em relação às economias industrializadas, mas cujas capacidades materiais desenvolveram-se em termos que lhes permitiram um grau de influência na economia global. ${ }^{10}$

Os modelos comportamental, comportamental-estrutural e crítico podem ser percebidos ao se distinguir as potências médias tradicionais das emergentes por meio da natureza de suas ações

9 Essa crítica de Schoeman (2000) é reconhecida inclusive no próprio trabalho de Cornelia Huelsz (2009, p. 14).

10 Tradução livre da autora. Texto original: "Emerging powers are those countries that are traditionally situated in different structural contexts to the industrialised economies, but whose material capabilities have developed on terms which have allowed a degree of influence in the global economy". 
Potências médias e potências emergentes na economia política...

Daniela Vieira Secches · Javier Alberto Vadell • Leonardo Ramos

em relação à promoção de mudanças globais. Os atores tradicionais tenderiam a apaziguar e a buscar legitimar o status quo sistêmico. Por outro lado, os novos atores médios apresentariam comportamento reformista a fim de legitimar sua própria inserção (JORDAAN, 2003, p. 168). Em sua primeira hipótese, Huelsz (2009, p. 67-68) menciona terem as potências médias emergentes uma identidade internacional forte e mais autônoma, característica também percebida por Jordaan (2003, p. 168) enquanto diferença comportamental. Essa identidade pode ser entendida como correlacionada à quarta hipótese de Huelsz (2009, p. 70) - qual seja, a de que as potências emergentes possuem caráter reformador.

Por fim, a terceira hipótese diferenciadora apresentada por Huelsz (2009, p. 69) aproxima-se dos modelos funcional e comportamental. A autora (2009, p. 16) propõe que:

O comportamento das potências emergentes tende a ser influenciado por uma agenda global diferente daquela das potências médias tradicionais, o que significa que as potências emergentes não necessariamente enfatizam o envolvimento em áreas que requerem um senso de responsabilidade ética ou moralmente infundida em direção à comunidade internacional. ${ }^{11}$

Cruzando os dados dos trabalhos que buscam diferenciar potências médias tradicionais e potências médias emergentes com os modelos teóricos desenhados para a compreensão de Estados que desfrutam uma posição intermediária de poder no ambiente internacional, podemos identificar as diferenças sumarizadas no quadro abaixo.

11 Tradução livre da autora. Texto original: "The behavior of emerging powers tends to be influenced by a different global agenda to that of the traditional middle powers, which means that emerging powers do not necessarily emphasize the involvement in issue areas that require a sense of ethically or morally infused responsibility towards the international community". 
Potências médias e potências emergentes na economia política...

Daniela Vieira Secches ·Javier Alberto Vadell • Leonardo Ramos

Tabela 4. Diferenças entre potências médias tradicionais e potências médias emergentes segundo os modelos teóricos identificados (JORDAAN, 2003; NOLTE, 2007; HUELSZ, 2009)

\begin{tabular}{|c|c|c|c|}
\hline MODELO TEÓRICO & $\begin{array}{l}\text { CRITÉRIO DE DIFE- } \\
\text { RENCIAÇÃ̃O }\end{array}$ & $\begin{array}{l}\text { POTÊNCIA MÉDIA } \\
\text { TRADICIONAL }\end{array}$ & $\begin{array}{l}\text { POTÊNCIA MÉDIA } \\
\text { EMERGENTE }\end{array}$ \\
\hline Funcional & Tipo de agenda. & $\begin{array}{l}\text { Agenda voltada para } \\
\text { questões ético-morais. }\end{array}$ & $\begin{array}{l}\text { Maior diversidade de } \\
\text { agenda. }\end{array}$ \\
\hline \multirow[b]{2}{*}{ Comportamental } & Tipo de agenda. & $\begin{array}{l}\text { Agenda voltada para } \\
\text { questões ético-morais. }\end{array}$ & $\begin{array}{l}\text { Maior diversidade de } \\
\text { agenda. }\end{array}$ \\
\hline & $\begin{array}{l}\text { Tipo de ação em } \\
\text { relação à estrutura } \\
\text { global. }\end{array}$ & $\begin{array}{l}\text { Apaziguadoras e legiti- } \\
\text { madoras do status quo. }\end{array}$ & $\begin{array}{l}\text { Reformadoras com vistas } \\
\text { a legitimar sua inserção } \\
\text { em uma estrutura reno- } \\
\text { vada. }\end{array}$ \\
\hline \multirow{4}{*}{ Sistêmico-estrutural } & Regime democrático. & $\begin{array}{l}\text { Tradição democrática } \\
\text { sólida. }\end{array}$ & $\begin{array}{l}\text { Tradição democrática } \\
\text { relativamente estável e } \\
\text { recente. }\end{array}$ \\
\hline & $\begin{array}{l}\text { Posição no sistema- } \\
\text {-mundo. }\end{array}$ & Centro. & Semiperiferia. \\
\hline & $\begin{array}{l}\text { Distribuição interna } \\
\text { de riqueza. }\end{array}$ & Igualitária. & Altamente desigual. \\
\hline & $\begin{array}{l}\text { Desenvolvimento de } \\
\text { capacidades mate- } \\
\text { riais. }\end{array}$ & $\begin{array}{l}\text { Mesmo contexto estru- } \\
\text { tural das economias } \\
\text { industrializadas. }\end{array}$ & $\begin{array}{l}\text { Contexto estrutural } \\
\text { diferente das economias } \\
\text { industrializadas. }\end{array}$ \\
\hline $\begin{array}{l}\text { Comportamental-estru- } \\
\text { tural }\end{array}$ & $\begin{array}{l}\text { Tipo de ação em } \\
\text { relação à estrutura } \\
\text { global. }\end{array}$ & $\begin{array}{l}\text { Apaziguadoras e legiti- } \\
\text { madoras do status quo. }\end{array}$ & $\begin{array}{l}\text { Reformadoras com vistas } \\
\text { a legitimar sua inserção } \\
\text { em uma estrutura reno- } \\
\text { vada. }\end{array}$ \\
\hline Inserção regional & $\begin{array}{l}\text { Relação com o am- } \\
\text { biente regional. }\end{array}$ & $\begin{array}{l}\text { Inserção pela função } \\
\text { exercida globalmente. }\end{array}$ & $\begin{array}{l}\text { Inserção enquanto po- } \\
\text { tência depende de ação } \\
\text { global combinada com } \\
\text { ação regional. }\end{array}$ \\
\hline Crítico & $\begin{array}{l}\text { Tipo de ação em } \\
\text { relação à estrutura } \\
\text { global. }\end{array}$ & $\begin{array}{l}\text { Apaziguadoras e legiti- } \\
\text { madoras do status quo. }\end{array}$ & $\begin{array}{l}\text { Reformadoras com vistas } \\
\text { a legitimar sua inserção } \\
\text { em uma estrutura reno- } \\
\text { vada. }\end{array}$ \\
\hline
\end{tabular}

Fonte: Elaborada pelos autores, com base em Cornelia Huelsz (2009); Deflte Nolte (2007) e Eduard Jordaan (2003).

Além dos critérios de diferenciação acima mencionados, a questão do marco temporal aparece recorrentemente na literatura (COOPER, 1997; JORDAAN, 2003; NOLTE, 2007; HUELSZ, 2009). Entende-se que as potências médias emergentes primordialmente se diferenciam das potências tradicionais pelo momento em que assumiram a condição de emergência - a partir da década de 1970. 
Potências médias e potências emergentes na economia política...

Daniela Vieira Secches ·Javier Alberto Vadell • Leonardo Ramos

A fim de compreender o comportamento dos Estados tidos como potências emergentes no século XXI nas esferas geopolítica, econômica e institucional, faz-se necessário determinar com mais clareza como as abordagens teóricas que qualificam potência média e diferenciam-nas entre tradicionais e emergentes apresentam-se. A partir do debate anteriormente feito e do cruzamento de seus dados, entende-se ser primordial uma diferenciação entre os aspectos conceituais que qualificam uma potência média como emergente (indicadores) ${ }^{12}$ daqueles que analisam os desdobramentos de um Estado que se alça a esse qualificativo (aspectos analíticos).

Tabela 5. Indicadores e aspectos analíticos contidos nas abordagens teóricas de Relações Internacionais sobre potências médias emergentes

\begin{tabular}{|c|c|}
\hline \multicolumn{1}{|c|}{ INDICADOR } & ASPECTO ANALÍTICO \\
\hline Emergência pós-1970 & Maior diversidade de agenda. \\
\hline $\begin{array}{c}\text { Regime democrático relativamente instável e } \\
\text { recente }\end{array}$ & $\begin{array}{c}\text { Reformadoras com vistas a legitimar sua inser- } \\
\text { ção em uma estrutura renovada }\end{array}$ \\
\hline Distribuição interna de riqueza altamente desigual & Posição semiperiférica no sistema-mundo \\
\hline $\begin{array}{c}\text { Desenvolvimento de capacidades materiais em } \\
\text { modelos distintos dos Estados industrializados }\end{array}$ & $\begin{array}{c}\text { Inserção como potência depende de ação global } \\
\text { combinada com ação regional }\end{array}$ \\
\hline
\end{tabular}

Fonte: Elaborada pelos autores.

A partir desse conceito de potência média emergente é que se pretendeu apontar no presente artigo a atuação de atores nos cenários globais do século XXI. Nesse sentido, e buscando avançar a partir das reflexões teórico-conceituais até aqui apresentadas, buscaremos, na seção seguinte, apresentar alguns dos principais elementos do que se considera um cenário geopolítico, econômico e institucional e seus aspectos mais relevantes no novo milênio. Feito isso, a título de conclusão, será discutido criticamente como as potências médias emergentes contemporaneamente se qualifi-

\footnotetext{
12 Faz-se importante esclarecer que não se pretende aqui debater os indicadores empíricos que qualificariam uma potência como média, e não como grande ou pequena. Trata-se de um debate importante, porém deveras complexo e além do escopo do presente trabalho. Por indicador, entende-se fatos empíricos que diferenciam, na literatura, uma potência média tradicional de uma potência média emergente.
} 
Potências médias e potências emergentes na economia política...

Daniela Vieira Secches ·Javier Alberto Vadell • Leonardo Ramos

cam e se inserem nesses cenários. Para isso, serão apresentados, então, alguns exemplos que nos permitam pensar a relação entre o conceito de poder e a definição de potência média emergente.

\section{Poder e emergência na economia política internacional contemporânea: breves apontamentos finais}

Mesmo antes do estabelecimento da primeira cátedra de Relações Internacionais, em 1919, na Universidade de Aberystwith, ${ }^{13}$ diversos autores debateram o conceito de poder - com importantes desdobramentos para nosso objeto de estudo. Peter Wilson (1995) discute autores chamados por alguns de idealistas do início do século XX, que teriam considerado as relações de cooperação e conflito na dimensão internacional, como Shaw e a obra Fabianismo e o Império (1900); Hobson e o Imperialismo (1902); Angell e Ilusão de Ótica da Europa (1908); Brailsford e A Guerra do Aço e do Ouro (1914); Dickinson e A Anarquia Europeia; e Woolf e o Governo Internacional (1916), dentre outros. Ao problematizar dimensões internacionais do Estado, os referidos autores lidam explicitamente com a problemática do poder. É ainda importante mencionar trabalhos como Imperialismo, face superior do capitalismo (1916), de Vladimir Lenin, que debate as questões de poder (expresso em termos políticos e econômicos) tendo em vista as relações coloniais da época.

O século XX testemunhou a consolidação do campo das Relações Internacionais e de abordagens teóricas mais autônomas, ainda que preservando a interdisciplinaridade intrínseca da área. Contemporaneamente, as teorias aplicadas a esse objeto po-

\footnotetext{
13 Em 1919, a Universidade de Aberysthwith, no País de Gales, recebeu uma vultuosa doação de David Davies para fundar uma cátedra dedicada a estudar a paz no ambiente internacional. Surgiu, assim, a Cátedra Woodrow Wilson, primeiro departamento dedicado exclusivamente a debates internacionais sobre guerra e paz. No entanto, a historiografia das Relações Internacionais, hoje, desafia essa data como marco formal do campo, haja vista a existência anterior de trabalhos que discutiam a mesma temática e a ausência de sistematicidade das discussões propostas na cátedra (DE CARVALHO, LEIRA, HOBSON, 2011).
} 
Potências médias e potências emergentes na economia política...

Daniela Vieira Secches ·Javier Alberto Vadell • Leonardo Ramos

dem ser divididas em teorias gerais e teorias específicas. ${ }^{14}$ As teorias gerais buscam analisar o objeto das Relações Internacionais em seus diversos aspectos. Elas subdividem-se em teorias clássicas e teorias contemporâneas, em função do marco temporal de seu surgimento e aplicação ao campo.

As chamadas teorias clássicas de Relações Internacionais, realismo e liberalismo, em suas diversas vertentes, compartilham um conceito-base de poder (ZAHREDDINE, TEIXEIRA, 2015, p. 2). Enquanto os realistas consideram-no como sinônimo de controle de recursos, especialmente na esfera militar; ${ }^{15}$ os liberais optam por uma abordagem mais relacional, por meio de complexos conceituais como a interdependência complexa. ${ }^{16}$ Cabe lembrar que ambas as produções teóricas são estatocêntricas, ou seja, procedem suas análises a partir da figura do Estado.

Hurrell (2006, p. 5-8) divide as contribuições das teorias clássicas de relações internacionais para o estudo do poder, e sua hierarquização em atores-potências, em duas perspectivas. A primeira, de natureza neorrealista, centra-se na distribuição do poder e nos comportamentos políticos resultantes. Poder aqui é entendido como capacidade material relativa, que seria traduzível em duas opções de ação externa: equilíbrio ou bandwagoning. A segunda perspectiva nasce da matriz liberal, que pode promover uma abordagem institucionalista ou sistêmica. Por um lado, considera-se as instituições relevantes para a compreensão do exercício do poder e sua relação com as normas internacionais. Por outro, no caso sistêmico, o significado mesmo de poder modifica-se pela interdependência complexa, impondo a liberalização econômica e a democratização do sistema capitalista como exemplos superiores e fontes hierarquizadas de poder.

\footnotetext{
14 Jackson e Sorensen (2013, p. 60) afirmam existir diversas categorias possíveis para a classificação das teorias aplicáveis ao objeto das Relações Internacionais, sendo que quaisquer classificação transforma-se, pois, em recurso meramente didático e não definidor de hierarquias.

15 As vertentes realistas sistêmicas depositam grande preocupação na distribuição de poder - entendido como capacidades, no sistema internacional, como no caso do realismo estrutural e do realismo ofensivo, por exemplo (WALTZ, 2002; MEARSHEIMER, 2001). Já as vertentes não-sistêmicas, como o realismo clássico, discutem poder considerando a natureza humana e estatal historicamente colocada (MORGENTHAU, 2003).

16 Para Keohane e Nye (2001), interdependência complexa é um tipo ideal do qual a realidade na segunda metade do século XX tende a se aproximar mais frequentemente. Nele, não existe hierarquia estável entre os interesses estatais, que se colocam sujeitos a trade-offs; há vários canais de comunicação entre diversos atores sociais, expandindo o alcance de instrumentos políticos além da chancelaria e a força militar é, em grande medida, irrelevante.
} 
As teorias contemporâneas de Relações Internacionais, em sua ampla diversidade, trazem recorrentemente um componente mais reflexivo para a análise do objeto do campo. Essa abordagem reflete-se em uma interpretação sobre poder que tende a levar em consideração, em geral, não apenas elementos materiais, mas também ideacionais (ZAHREDDINE, TEIXEIRA, 2015, p. 73). Aqui, considerações epistemológicas mediativas sobre a relação entre agente e estrutura, bem como análises sistêmicas envolvendo atores além do Estado, ganham espaço e incluem nos debates sobre poder outros conceitos como identidade, classe, gênero e relações coloniais.

Há, ainda, as chamadas teorias específicas de Relações Internacionais. Elas se configuram em colaborações de campos correlatos para a análise de determinados fenômenos contidos no objeto das Relações Internacionais. Exemplos são encontrados em disciplinas como Integração Regional, Análise de Política Externa, Desenvolvimento e Economia Política Internacional. Por vezes, elas mantém uma relação epistemológica próxima com as abordagens gerais e é possível encontrar semelhanças na maneira como lidam com o conceito de poder e potência aplicados ao seu recorte analítico.

Como sustentado ao longo do artigo, entende-se que, para compreender como a ideia de poder pode ser desdobrada no conceito de potência, os modelos teóricos encontrados na Economia Política Internacional apresentam uma interessante opção, com a capacidade de reunir elementos desse subcampo com as abordagens teóricas gerais de Relações Internacionais. Não se pode deixar de lado que esses modelos analíticos carregam certo estadocentrismo ao trabalhar com a noção de potência como um qualificativo de Estado, a despeito de eventualmente incluir em suas análises outros tipos de atores e processos como elementos relevantes para a reflexão sobre as origens e as consequências dessa circunstância.

A discussão sobre potências emergentes nas Relações Internacionais remonta ao debate sobre potências médias tradi- 
cionais surgidas no pós-Segunda Guerra Mundial. Diversos teóricos observaram, nesse período, o renovado papel de Estados como Canadá e Austrália no contexto de uma distribuição bipolar de poder entre duas grandes potências - EUA e URSS. Na década de 1970, contudo, percebeu-se que novos poderes emergiam em condição intermediária e começou-se a discutir, em especial na Economia Política Internacional, como qualificá-los, diferenciá-los dos Estados médios tradicionais, bem como compreender seu impacto no sistema internacional.

É possível, no século XXI, testemunhar uma continuidade dessa linha de investigação. O fim da Guerra Fria na década de 1990 e a diversidade e a complexidade que permeia o sistema internacional do novo milênio fizeram aumentar a curiosidade teórica sobre as chamadas potências emergentes. Discutiu-se aqui, brevemente, o estado da arte desse debate. Os seis modelos encontrados para conceituar potências médias e suas interfaces com o debate sobre a emergência de novos intermediários apresentam, todos, suas limitações específicas, que derivam da própria diversidade de formas de se conceituar e aferir o poder nas Relações Internacionais.

Para melhor refletir acerca do papel dos emergentes no século XXI, no entanto, faz-se necessária uma agenda de pesquisa que busque esclarecer o potencial explicativo dos diferentes indicadores de poder médio que são atualmente utilizados, bem como seus consequentes aspectos analíticos. Esse movimento é importante para se evitar uma confusão tautológica, relativamente comum na literatura especializada, entre fatores que indicam uma hierarquia média de poder e as consequências comportamentais de Estados que se encontram nessa faixa. A conjuntura internacional deve, ainda, servir como parâmetro relevante para a validação do conceito, considerando-se o poder da emergência em conjunto com a própria crise nesses países, especialmente a partir de 2015. Nesse cenário, a divisão Norte-Sul e a diminuição do poder dos Estados Unidos da América como eixos a partir dos quais o conceito de emergência fora previamente cunhado - e, em alguns casos, louvado - começam a ser revisitados, levantando senão novos limites 
para o potencial analítico da ideia de potência média emergente, ao menos novos questionamentos acerca do limites e possibilidades concretas de emergência na economia política internacional contemporânea (KIELY, 2016).

Não se quer, contudo, sugerir a busca de um modelo definitivo - a multiaspectualidade do campo tornaria esforços nesse sentido infrutíferos. Todavia, é preciso entender os limites explicativos das abordagens propostas. Nesse sentido, instrumentos como a estatística descritiva e multivariada utilizada por Zahreddine e Teixeira (2015), e estudos exploratórios como o proposto por Nolte (2007) em How to Compare Regional Powers: Analytical Concepts and Research Topics, são de grande valia. Outra questão importante é considerar os movimentos contra-hegemônicos promovidos por Estados qualificados como potências médias emergentes, o que leva Jordaan (2017), por exemplo, a considerar dessa forma apenas os países que se alinham na defesa da ordem liberal.

Outra interessante agenda seria o debate sobre casos limítrofes quando se atribui o qualificativo de potência média - seja no sentido tradicional ou emergente. China e Índia não são vistas por Jordaan (2003, p. 167) como potências emergentes, por exemplo, a despeito de diversos outros trabalhos identificarem um padrão de comportamento comum entre esses Estados e outros países que são mais consensualmente aceitos como emergentes (HURRELL, 2006; NARLIKAR, 2010; HUELSZ, 2009). Em sentido semelhante, um caso ainda mais curioso é o da Rússia. Com o fim da Guerra Fria, tornou-se mais ainda questionável o status de potência que poderia ser atribuído à sucessora da União Soviética, diante da consolidação do poder estadunidense e da crise interna vivida na Rússia. Observando os critérios de Jordaan (2003, p. 167), que exclui da lista de potências médias Estados nuclearizados, não seria possível considerar os russos enquanto emergentes. Por outro lado, tampouco entrariam na acepção de potências médias tradicionais, considerando o fato de, à época do surgimento dessas, ser o Kremlin indubitavelmente um dos dois eixos de grande poder glo- 
Potências médias e potências emergentes na economia política...

Daniela Vieira Secches · Javier Alberto Vadell • Leonardo Ramos

bal, além de ter um comportamento e uma agenda externa bem diferentes de Austrália e Canadá atualmente, por exemplo.

Hurrell (2006) faz um esforço para mencionar exemplos empíricos que colocariam a Rússia como potência emergente, mas seu poder explicativo é patentemente menor do que a análise feita pelo autor sobre os outros casos que estuda - Brasil, China e Índia. MacFarlance (2009) vai além na discussão feita por Hurrell (2006), por meio de uma análise mais sistemática. De qualquer forma, diante de uma grande pluralidade teórica sobre o conceito, associada a poucos estudos empíricos sobre o caso russo, seria interessante incluir de forma mais incisiva esse Estado na agenda de pesquisa sobre os emergentes no século XXI. Seu peso geopolítico regional (MIELNICZUK, 2013); o tamanho de sua economia e seu crescimento no novo milênio; bem como seu papel na reconfiguração institucional internacional, como membro permanente do Conselho de Segurança das Nações Unidas, e protagonismo em outras estruturas, como os BRICS, são motivações suficientes para sustentar essa sugestão ${ }^{17}$.

Por fim, mas não menos importante, a abordagem crítica sobre o tema promovida por autores como Ramos $(2013$; 2014) e Huelsz (2009) é fundamental para se considerar o potencial transformativo dos emergentes no contexto de uma ordem internacional significativamente plural, aberta e complexa. A continuidade de estudos de caso, bem como de proposições teórico-empíricas, sobre como as potências emergentes atuam para promover mudanças no sistema internacional contemporâneo assume, ainda, função de grande relevância em um cenário de recorrentes crises econômicas, sociais e políticas, o que as coloca como atores fundamentais das Relações Internacionais do século XXI.

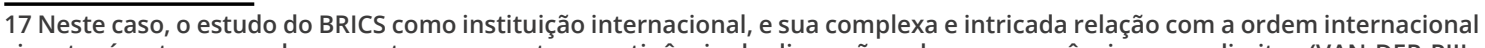
vigente, é outro exemplo concreto que aponta a pertinência da discussão sobre a emergência e seus limites (VAN DER PIJL, 2017; RAMOS et al., 2018). 
Potências médias e potências emergentes na economia política...

Daniela Vieira Secches · Javier Alberto Vadell • Leonardo Ramos

\section{Referências}

CARR, EdWARD. Vinte ANOS de CRISE: 1919-1929. TRADUZIDO POR LUIZ

Alberto Figueiredo Machado. Brasília: UnB, [1939] 2001. P. 135.

Cervo, Amado Luiz; BUENO, Clodoaldo. História da política exterior do Brasil. Brasília: UnB, 2008.

COOPER, Andrew; HIGGOT, Richard; NOSSAL, Kim. Relocating Middle

Powers: Australia and Canada in a Changing World order. Vancouver:

University of British Columbia, 1993.

COX, Robert. Middlepowermanship, Japan, and Future World Order,

INTERNATIONAL JOURNAL, V. 44, N. 4, P. 823-832, 1989.

DE CARVAlHo, Benjamin; LeIRA, Halvard; hOBSON, John. The Big Bangs of IR: The Myths That Your Teachers Still Tell You about 1648 and 1919. Millenium, v. 39, N. 75, P. 735-758, 2011.

Gelber, Lionel Canada's New Stature. Foreign Affairs, v. 24, N. 2, P. 277-289, 1946.

GiacCAglia, Clarisa. Poderes emergentes: ¿todo es sólo para la foto? El Caso de Brasil, Estudos Internacionais, v. 2, N. 1, p. 101-115, 2014.

HOlBraAd, Carsten. Middle Powers in International Politics. Londres: MacMillan Press, 1984.

HUElSZ, Cornelia. Middle Power theories and emerging powers in international political eConomy: a case study of Brazil. TeSe de doutoramento. Manchester: University of Manchester, 2009.

HURRELL, Andrew. Hegemony, liberalism ANd Global order: What SPACE for Would-be Great powers? International Affairs, v. 82, N.1, P. 1-19, 2006. 
Potências médias e potências emergentes na economia política...

Daniela Vieira Secches · Javier Alberto Vadell • Leonardo Ramos

JORDAAN, EduARD. The CONCEPT OF A MIDDLE POWER IN INTERNATIONAL RELATIONS: DISTINGUISHING BETWEEN EMERGING AND TRADITIONAL MIDDLE POWERS. Politikon, v. 30, N. 1, P. 165-181, 2003.

JORDAAN, EduARd. The EMERGING MidDLE POWER CONCEPT: TIME TO SAY GOODbye? South African Journal of Internacional Affairs, p. 1-17, 2017. KEOHANE, Robert. Lilliputians'Dilemmas: small states In INTERnational Relations. International Organizations, v. 23, n. 2, P. 291-310, 1969. KIELY, Ray. The RISE ANd fall OF EMERgING POWERs: GLOBALISATION, US POWer and the global North-South divide. Basingstoke: Palgrave Macmillan, 2016.

lima, Maria Regina Soares de. The Political Economy of Brazilian Foreign Policy: nuclear Energy, Trade and Itaipu. Brasília: FUnAG, 2013. MACFARLANCE, NeIL. O “R" dOS BRICS: A RúSSIA É UMA POTÊNCIA EMERgente? In: NARlikAR, Amrita et al. Os Brics e a Ordem Global. Rio de JANEIRO: FGV, 2009.

MEARSHEIMER, John. The tragedy of great power politics. New York: W. W. NORTON \& COMPANY, 2001.

MiELNiCZUK, Fabiano. O Conflito entre Rússia e GeÓrgia: uma revisão HistóRICA. Estudos Internacionais, v. 1, N. 2, P. 157-166, 2013.

morgenthaU, Hans. A Política entre as Nações. Traduzido por Oswaldo Biato. Brasília: UnB, 2003.

MYers, David. Threat Perception and Strategic Response of Regional Hegemons: a conceptual overview. In: MYeRS, David. Regional Hegemons: threat perception and strategic responses. São Francisco: WestView Press, 1991. 
Potências médias e potências emergentes na economia política...

Daniela Vieira Secches · Javier Alberto Vadell • Leonardo Ramos

NARLIKAR, AmritA. New powers: how to beCome one AND hOW to MANAge them. Nova lorque: Columbia University Press, 2010.

NOlte, Detlef. How to Compare Regional Powers: Analytical Concepts and Research Topics. Trabalho apresentado em ECPR Joint Session

Workshops, Helsinki, 7 a 12 de Maio de 2007. Disponível EM hTtP://ECPR. eu/Filestore/PaperProposal/212A550d-597b-4F60-86dF-ec73a8e43707. PDF. ACESSO EM 10 DE JUNHO DE 2015.

OSterud, Oyvind.. Regional Great Powers. In: NeUMANN, Iver (ed.).

Regional Great Powers in International Politics. Basingstoke: St.

Martin's PRess, P. 1-15, 1992.

VAN DER PIJL, KESS. THE BRICS - AN INVOLUNTARY CONTENDER BLOC UNDER ATtACK. Estudos Internacionais, v. 5, N. 1, P. 25-46, 2017.

Ramos, leonardo. Pensando Criticamente a Economia Política Global: apontamentos para o estudo de potênCias médias emergentes. Austral:

Revista Brasileira de Estratégia e Relações Internacionais, v. 2, N. 3, P. 233-256, 2013.

RamoS, Leonardo. Potências Médias Emergentes e Reforma da

Arquitetura Financeira Mundial? Uma análise do BRICS e do G20. Revista de Sociologia e Política, v. 22, N. 50, P. 233-256, 2014.

Ramos, Leonardo, et. al. A Decade of Emergence: The BRICS' Institutional Densification Process. Journal of China and International Relations, v. 6, Special issue, P. 1-15, 2018.

SCHNEIDER, Robert. Brazil: foreign policy of A future World poWer. São Francisco: WestView Press, 1977.

SelCher, Wayne. O Brasil no Sistema Mundial de Poder. Revista

Brasileira de Política Internacional, v. 26, N.101-104, P. 83-91, 1983. 
Potências médias e potências emergentes na economia política...

Daniela Vieira Secches · Javier Alberto Vadell • Leonardo Ramos

SENNES, Ricardo. PotênCia MÉdia RecÉm-Industrializada: PARÂMetros Para analisar o Brasil. Contexto Internacional, v. 20, n. 2, P. 385-413, 1998.

WAllerstein, Immanuel. O Sistema Mundial Moderno. Porto:

Afrontamento, 1990.

WALTZ, Kenneth. Teoria das Relações internacionais. Traduzido por

Maria Luísa Felgueiras Gayo. Lisboa: Gradiva, 2002.

ZAHREDDINE, Danny; TEIXEIRA, Rodrigo. A ORdem Regional no Oriente

Médio 15 anos após os atentados de 11 de Setembro. Revista de Sociologia

PolíticA, v. 23, N. 53, P. 71-98, 2015. 